\title{
Causes of intraspecific variation in body size among trematode metacercariae
}

\author{
I. Saldanha, T.L.F. Leung and R. Poulin* \\ Department of Zoology, University of Otago, PO Box 56, Dunedin 9054, \\ New Zealand
}

\begin{abstract}
Inequalities in body size among adult helminths can result in inequalities in reproductive output, with consequences for population dynamics and genetics. These inequalities can result from growth differences among larval worms inside intermediate hosts that persist into the adult stage. Here, we investigate the effects of both host body size and intensity of infection on the sizes of metacercariae of the trematode Maritrema novaezealandensis (Microphallidae) inside their second intermediate host, the isopod Paridotea ungulata (Idoteidae). Among the more than 1500 metacercariae recovered and individually measured, there was no relationship between the mean diameter of metacercarial cysts per isopod and isopod body length. However, intensity of infection correlated negatively with the mean diameter of cysts within an isopod, i.e. metacercariae in crowded infections attained smaller sizes on average. In contrast, the variability in cyst sizes per isopod, measured as the coefficient of variation, was independent of both isopod body length and infection intensity. Our results show that a disproportionate number of relatively small metacercariae come from the relatively few hosts in which a large fraction of all metacercariae are aggregated. The combination of aggregation and intensity-dependent growth generates inequalities in sizes among metacercariae that will be passed on to adult worm populations in definitive hosts.
\end{abstract}

\section{Introduction}

In most helminths, the fecundity of individual worms is roughly proportional to their body size: larger worms produce more eggs than smaller ones (Poulin, 1995, 1996). In many species, there are considerable inequalities in body sizes among adult worms (Shostak \& Dick, 1987; Szalai \& Dick, 1989; Poulin \& Latham, 2002). This typically leads to the disproportionate contribution of a few large individuals to the overall egg output of the parasite population. From the perspective of parasite population genetics, this phenomenon can greatly reduce the effective population size (Dobson, 1986; Criscione \& Blouin, 2005). The variation in body sizes among individual worms in a population is thus a crucial facet of parasite population biology, and it is important to understand the factors that generate this variation.

*E-mail: robert.poulin@stonebow.otago.ac.nz
Earlier studies have attributed size inequalities among parasitic worms to different infection times and/or intense competition for space and other resources in the definitive host (Dobson, 1986; Shostak \& Dick, 1987; Szalai \& Dick, 1989). These studies, however, all focused on helminth species that are relatively large compared to the volume of the organ (e.g. the intestine) they occupy within the definitive host. In the case of species with much smaller body sizes, competition and other resourcebased processes taking place in the definitive host may have little bearing on variation in body sizes among individuals. In contrast, small helminth species may be more likely to face these sorts of pressures earlier in their life cycle, when they inhabit smaller-sized invertebrate intermediate hosts. Indeed, many larval helminths display reduced growth when sharing an intermediate host with even just a few conspecifics (e.g. Sandland \& Goater, 2000; Dezfuli et al., 2001; Brown et al., 2003; Fredensborg \& Poulin, 2005). Inequalities in body sizes among larval helminths can be transferred to the adult 
stage, assuming that larval size correlates with adult size (see Poulin \& Latham, 2003).

The trematode Maritrema novaezealandensis (Microphallidae), a common parasite in coastal areas of New Zealand, is a species in which adult sizes are likely to be influenced by processes acting on juvenile (metacercarial) stages in intermediate hosts. Adult worms live in the digestive tract of gulls, but their generally small size (about $350 \mu \mathrm{m}$ body length on average) (Martorelli et al., 2004) and low intensities of infection make it unlikely that competition for resources will constrain their sizes. In contrast, the metacercariae in the body cavity of the small crustaceans (mostly amphipods and isopods), serving as intermediate hosts, are relatively large compared to the space available. There is evidence of intensity-dependent growth in metacercariae of this species (Fredensborg \& Poulin, 2005), and even of a limit on how many metacercariae can be accommodated by one of these small crustaceans without killing it (Fredensborg et al., 2004). On the one hand, space and nutrient availability within the host can constrain metacercarial growth, with larger hosts allowing metacercariae to reach larger sizes. On the other hand, intensitydependent effects can influence not only the average size achieved by metacercariae, but also the variance in their sizes if different infection times result in a priority advantage for the first parasites to infect a host. Thus, crowded infections may lead to generally smaller and more variable sizes among individual metacercariae.

Here, we investigate the variability in body size among metacercariae of $M$. novaezealandensis in one of their intermediate hosts, the isopod Paridotea ungulata (Idoteidae). This is the first record of this crustacean serving as intermediate host for this trematode species, though given that this is a common species in intertidal areas of New Zealand (Poore \& Lew Ton, 1993), where the trematode completes its life cycle, and given the lack of specificity of $M$. novaezealandensis for its second intermediate hosts, this isopod is probably a commonly used route toward the definitive bird host. We evaluate the respective effects of host size and intensity of infection on both the average size of metacercariae per host and its variance, in order to determine what factors regulate the sizes of parasites recruited to adult worm populations in avian final hosts.

\section{Materials and methods}

Isopods were collected in April 2008 from Lower Portobello Bay, Otago Harbour, South Island, New Zealand. They were collected at low tide from puddles on a large expanse of eelgrass (Zostera capricorni), by dragging dipnets (mesh size $1 \mathrm{~mm}$ ) along submerged vegetation. All isopods were returned live to the laboratory, placed in tanks and maintained in aerated seawater with sea lettuce (Ulva reticulata) as food, at room temperature, for several days until dissection.

Each isopod was measured (body length, from anterior end to tip of uropod) prior to dissection. All parts of the body were searched for parasites, including the appendages; the only parasites recovered were metacercariae of M. novaezealandensis. The number of metacercariae per host was recorded for each isopod, before the maximum diameter of each metacercarial cyst was determined using a calibrated eyepiece (at $100 \times$ magnification) on a compound microscope. For each isopod, the mean cyst diameter of all metacercariae harboured was calculated, as well as their coefficient of variation $(100 \times$ mean/standard deviation).

The numbers of metacercariae per isopod were $\log _{10}$-transformed to meet the assumptions of normality [ $\log _{10}(x+1)$ when uninfected isopods were included]; none of the other variables required transformation. All statistical analyses involved standard parametric tests.

\section{Results}

A total of 1510 metacercariae of $M$. novaezealandensis were recovered from 49 isopods. These isopods ranged in body length from 5 to $35 \mathrm{~mm}$ (mean $\pm \mathrm{SE}: 17.8 \pm 1.1 \mathrm{~mm}$ ). Only $34(69.4 \%)$ of the 49 isopods harboured metacercariae, with infected individuals generally being longer than uninfected ones (mean $\pm \mathrm{SE}$ : infected, $20.5 \pm 0.9 \mathrm{~mm}$, $N=34$; uninfected, $11.8 \pm 2.3 \mathrm{~mm}, N=15$; two-tailed $t$ test: $t=3.44, P=0.0028)$. The numbers of metacercariae per isopod ranged from 1 to 170 , with the majority of isopods harbouring fewer than 20 metacercariae (fig. 1). However, approximately $70 \%$ of the metacercariae were concentrated in slightly less than $30 \%$ (i.e. the ten most heavily infected) of the infected isopods, indicating that most individuals develop in crowded conditions within the second intermediate hosts.

The number of metacercariae per isopod correlated positively with isopod body length, but only if the relationship included all isopods $(r=0.494, N=49$, $P=0.0003)$; when only infected ones are included, the correlation disappeared $(r=0.252, N=34, P=0.1499)$. Therefore, the link between host body size and the number of metacercariae harboured is very weak: among infected isopods, body length explained only about $6 \%$ of

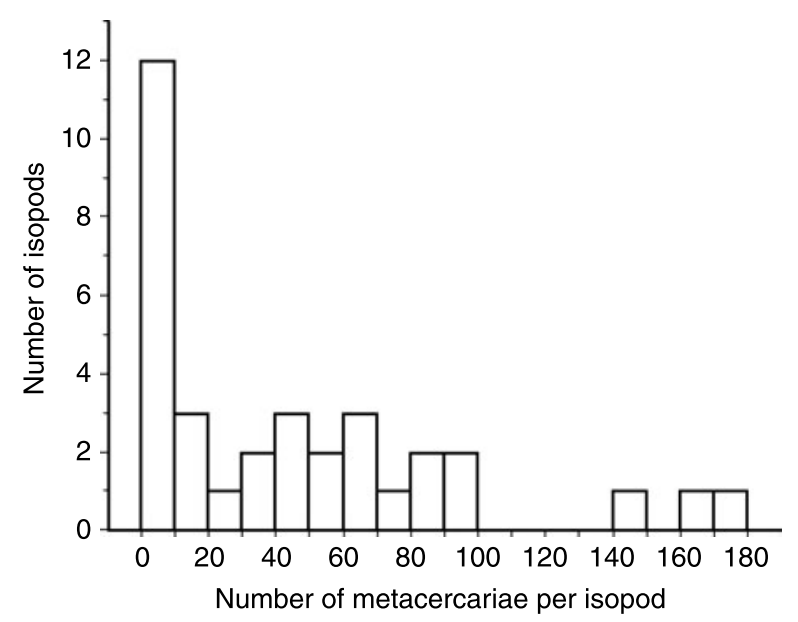

Fig. 1. Frequency distribution of intensities of infection by metacercariae of Maritrema novaezealandensis among isopods (Paridotea ungulata). Note: these data include only infected isopods $(N=34)$. 
the variance in intensity of infection. Host body length and intensity of infection can thus be considered as independent factors that may each influence the size achieved by metacercariae.

Overall, across all 1510 metacercariae recovered, cyst diameter ranged from 122 to $476 \mu \mathrm{m}$ (mean $=245 \mu \mathrm{m})$, with the majority falling between 200 and $280 \mu \mathrm{m}$ in diameter (fig. 2). Using a multiple regression to test for the respective effects of isopod body length and intensity of infection on the mean diameter of metacercarial cysts in an isopod, we found that isopod body length had a weak but non-significant positive effect on average cyst diameter $\left(F_{1,31}=3.105, P=0.0879\right)$, whereas intensity of infection had a significant negative effect $\left(F_{1,31}=9.933\right.$, $P=0.0036)$. Thus, the greater the number of metacercariae per isopod, the smaller they will be on average, regardless of isopod body size (fig. 3). However, the variability in cyst diameter, measured as the coefficient of variation among metacercariae within the same isopod, was not related to either isopod body length (multiple regression: $\left.F_{1,29}=1.040, P=0.3162\right)$ or intensity of infection $\left(F_{1,29}=0.0004, P=0.9843\right)$.

\section{Discussion}

Variation in body size among individuals in a parasite population has important implications for population dynamics and genetics, since inequalities in body sizes among individual parasites generally translate into differences in adult fecundity, and thus in uneven contributions to the next generation's gene pool (Dobson, 1986; Shostak \& Dick, 1987; Criscione \& Blouin, 2005). Here, we provide evidence that, at least in the trematode $M$. novaezealandensis, growth conditions in the second intermediate host generate variation in the size of metacercarial cysts. Since metacercariae ingested by birds form the basis of the adult worm population, the variability in body

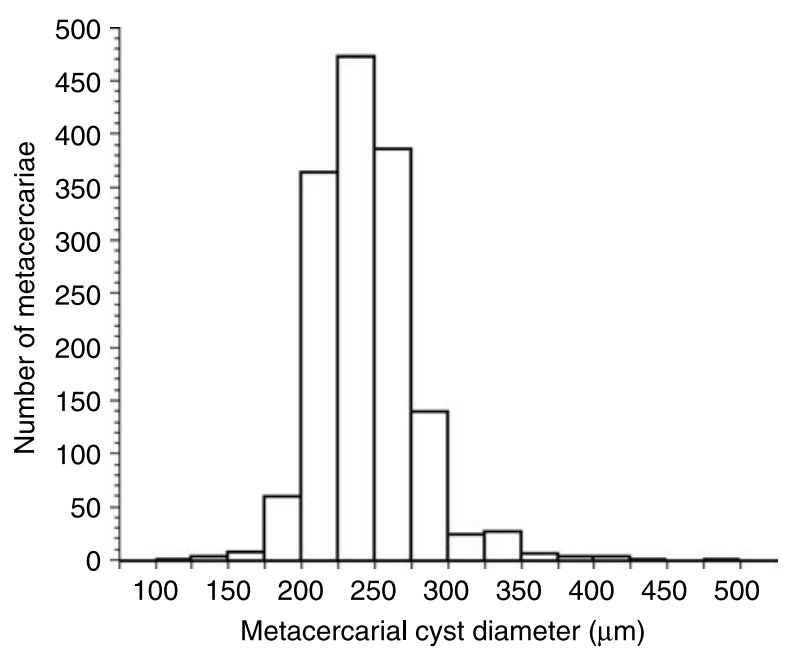

Fig. 2. Frequency distribution of cyst diameters among the 1510 metacercariae of Maritrema novaezealandensis recovered from infected isopods (Paridotea ungulata).

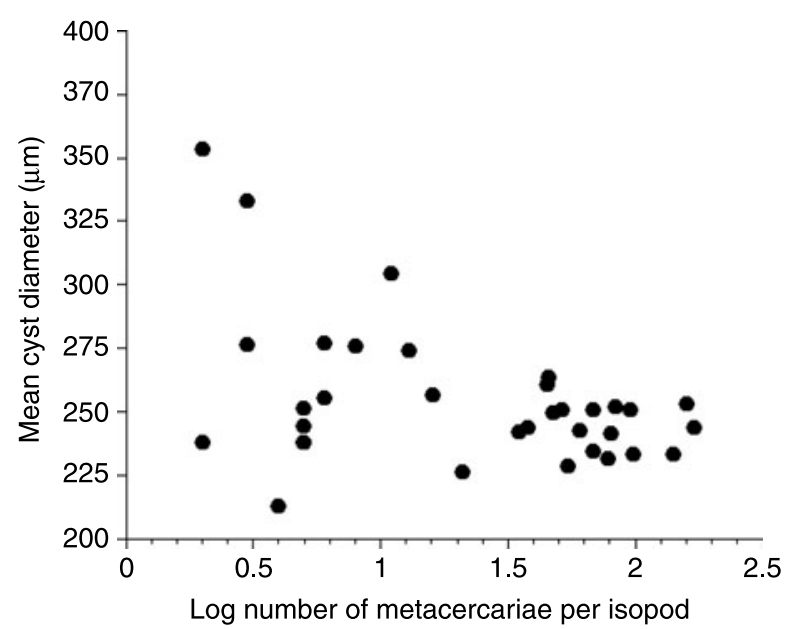

Fig. 3. Relationship between the mean diameter of metacercarial cysts and the number of Maritrema novaezealandensis metacercariae per host among 34 infected isopods (Paridotea ungulata).

sizes existing among metacercariae leads to initial variability among adult worms, with possible consequences for inter-individual differences in reproductive output.

The size of isopod intermediate hosts was only very weakly correlated with the number of metacercariae acquired by the host over its lifespan. Although in many host-parasite systems larger hosts tend to harbour more parasites than small ones, as seen in this study this tendency is marginal, at best, in the case of microphallid trematodes infecting crustacean hosts like shrimps or isopods (see also Pung et al., 2002; Ferreira et al., 2005; Hansen \& Poulin, 2005). Therefore, host size and intensity of infection can be seen as more-or-less independent factors acting on metacercarial growth. Large host sizes should allow for more resources and enhanced metacercarial growth, whereas high infection intensities should lead to crowding and intense competition for resources, and thus to reduced growth.

Our results suggest that intensity of infection is the most important factor in our system. Despite sevenfold differences in body length among individual isopod hosts in our sample, there seem to be few advantages in terms of growth incurred by a metacercaria inside a large isopod. One reason for this is that many metacercariae may have arrived inside an isopod when the latter was small. Metacercarial growth, from cercarial penetration to full encystment, occurs over just a few weeks, and as the host grows subsequently, the final metacercarial size will not change. Whatever the exact reasons, it was intensity of infection, and not host body size, that mattered the most for metacercarial size in our study. Earlier studies have also reported a negative impact of crowding on metacercarial size (Brown et al., 2003; Fredensborg \& Poulin, 2005), and some form of direct competition for resources seems the likely reason. Among the total number of metacercariae recovered in this study, a disproportionate number of the small ones (cyst diameter 
$<225 \mu \mathrm{m}$ ) originate from isopods harbouring 50 or more cysts, highlighting just how crowding forces a considerable proportion of the metacercarial population to remain below the average size. Since the size of the first few metacercariae to infect an isopod becomes fixed following full encystment, it must be later arrivals that experience reduced growth rate as a consequence of numerous prior metacercariae already established within the host. In addition to resulting in lower average sizes, crowding as a result of multiple infections staggered over time should also result in highly variable metacercarial sizes. However, there was no evidence in our analyses that intensity of infection affected the within-host variability in cyst dimensions (see also Fredensborg \& Poulin, 2005).

In general, large-sized helminth larvae have an advantage over smaller conspecifics when they reach the definitive host. For instance, larger acanthocephalan cystacanths have greater establishment success than small ones (Steinauer \& Nickol, 2003), and larger metacercariae achieve greater fecundity than small ones (Lagrue \& Poulin, 2007). In M. novaezealandensis, larger cysts contain larger worms, and these larger worms have a higher initial egg output than smaller worms issued from small cysts when they reach the definitive host (Fredensborg \& Poulin, 2005). Thus the size differences among metacercariae in intermediate hosts can have repercussions at the adult stage, as measured by several fitness components.

Of course, other factors can also act to create variability in sizes among metacercariae. For instance, in many trematodes, second intermediate hosts that accumulate large numbers of metacercariae tend to acquire a huge variety of parasite genotypes; in other words, they become infected by many of the different cercarial genotypes produced by molluscan first intermediate hosts (Rauch et al., 2005; Keeney et al., 2007; Leung et al., 2008). If, all else being equal, there are genetically based differences in metacercarial growth among trematode genotypes, then these will also contribute to variability in metacercarial sizes. Nevertheless, the significant effect of infection intensity found in the present study demonstrates that crowding is an important factor shaping the distribution of parasite body sizes within trematode populations. Indeed, the combined effects of aggregation and intensity-dependent growth determine the shape of the size distribution of metacercariae (shown in fig. 3), causing its mode to be shifted toward smaller sizes. The fact that $M$. novaezealandensis also uses other crustacean species as second intermediate hosts (see Martorelli et al., 2004) can only exacerbate the size differences among metacercariae founding adult populations inside birds. Some of these hosts (amphipods) are smaller and have lower infection intensities, and some (crabs) are larger and have higher infection intensities than the isopod $P$. ungulata that was the focus of this study. As a consequence, there must be substantial variability among the sizes of metacercariae founding adult populations in bird intestines. With the initial founders already showing inequalities in body sizes, any subsequent mechanisms causing differential growth within the definitive host would only intensify later inequalities in reproductive output.

\section{References}

Brown, S.P., De Lorgeril, J., Joly, C. \& Thomas, F. (2003) Field evidence for density-dependent effects in the trematode Microphallus papillorobustus in its manipulated host, Gammarus insensibilis. Journal of Parasitology 89, 668-672.

Criscione, C.D. \& Blouin, M.S. (2005) Effective sizes of macroparasite populations: a conceptual model. Trends in Parasitology 21, 212-217.

Dezfuli, B.S., Giari, L. \& Poulin, R. (2001) Costs of intraspecific and interspecific host sharing in acanthocephalan parasites. Parasitology 122, 483-489.

Dobson, A.P. (1986) Inequalities in the individual reproductive success of parasites. Parasitology 92, $675-682$.

Ferreira, S.M., Jensen, K.T., Martins, P.A., Sousa, S.F., Marques, J.C. \& Pardal, M.A. (2005) Impact of microphallid trematodes on the survivorship, growth, and reproduction of an isopod (Cyathura carinata). Journal of Experimental Marine Biology and Ecology 318, 191-199.

Fredensborg, B.L. \& Poulin, R. (2005) Larval helminths in intermediate hosts: does competition early in life determine the fitness of adult parasites? International Journal for Parasitology 35, 1061-1070.

Fredensborg, B.L., Mouritsen, K.N. \& Poulin, R. (2004) Intensity-dependent mortality of Paracalliope novizealandiae (Amphipoda: Crustacea) infected by a trematode: experimental infections and field observations. Journal of Experimental Marine Biology and Ecology 311, 253-265.

Hansen, E.K. \& Poulin, R. (2005) Impact of a microphallid trematode on the behaviour and survival of its isopod intermediate host: phylogenetic inheritance? Parasitology Research 97, 242-246.

Keeney, D.B., Waters, J.M. \& Poulin, R. (2007) Clonal diversity of the marine trematode Maritrema novaezealandensis within intermediate hosts: the molecular ecology of parasite life cycles. Molecular Ecology 16, $431-439$.

Lagrue, C. \& Poulin, R. (2007) Life cycle abbreviation in the trematode Coitocaecum parvum: can parasites adjust to variable conditions? Journal of Evolutionary Biology 20, 1189-1195.

Leung, T.L.F., Poulin, R. \& Keeney, D.B. (2008) Accumulation of diverse parasite genotypes within the bivalve second intermediate host in the digenean Gymnophallus sp. International Journal for Parasitology, in press.

Martorelli, S.R., Fredensborg, B.L., Mouritsen, K.N. \& Poulin, R. (2004) Description and proposed life cycle of Maritrema novaezealandensis n.sp. (Microphallidae) parasitic in red-billed gulls Larus novaehollandiae scopulinus from Otago Harbor, South Island, New Zealand. Journal of Parasitology 90, 272-277.

Poore, G.C.B. \& Lew Ton, H.M. (1993) Idoteidae of Australia and New Zealand (Crustacea: Isopoda: Valvifera). Invertebrate Taxonomy 7, 197-278.

Poulin, R. (1995) Evolution of parasite life history traits: myths and reality. Parasitology Today 11, 342-345. 
Poulin, R. (1996) The evolution of life history strategies in parasitic animals. Advances in Parasitology 37, 107-134.

Poulin, R. \& Latham, A.D.M. (2002) Inequalities in size and intensity-dependent growth in a mermithid nematode parasitic in beach hoppers (Amphipoda: Talitridae). Journal of Helminthology 76, 65-70.

Poulin, R. \& Latham, A.D.M. (2003) Effects of initial (larval) size and host body temperature on growth in trematodes. Canadian Journal of Zoology 81, 574-581.

Pung, O.J., Khan, R.N., Vives, S.P. \& Walker, C.B. (2002) Prevalence, geographic distribution, and fitness effects of Microphallus turgidus (Trematoda: Microphallidae) in grass shrimp (Palaemonetes spp.) from coastal Georgia. Journal of Parasitology 88, 89-92.

Rauch, G., Kalbe, M. \& Reusch, T.B.H. (2005) How a complex life cycle can improve a parasite's sex life. Journal of Evolutionary Biology 18, 1069-1075.

Sandland, G.J. \& Goater, C.P. (2000) Development and intensity dependence of Ornithodiplostomum ptychocheilus metacercariae in fathead minnows (Pimephales promelas). Journal of Parasitology 86, 1056-1060.

Shostak, A.W. \& Dick, T.A. (1987) Individual variability in reproductive success of Triaenophorus crassus Forel (Cestoda: Pseudophyllidea), with comments on use of the Lorenz curve and Gini coefficient. Canadian Journal of Zoology 65, 2878-2885.

Steinauer, M.L. \& Nickol, B.B. (2003) Effect of cystacanth body size on adult success. Journal of Parasitology 89, $251-254$.

Szalai, A.J. \& Dick, T.A. (1989) Differences in numbers and inequalities in mass and fecundity during the eggproducing period for Raphidascaris acus (Nematoda: Anisakidae). Parasitology 98, 489-495.

(Accepted 15 December 2008)

First Published Online 16 February 2009 (C) 2009 Cambridge University Press 